\title{
IMPACT OF RETROGRADE CEREBRAL PERFUSION ON AORTIC ARCH ANEURYSM REPAIR
}

Marek P. Ehrlich, MD

W. Christopher Fang, MD, MHSc ${ }^{\mathrm{b}}$

Martin Grabenwöger, MD

Alfred Kocher, MD

Jan Ankersmit, MD

Guenther Laufer, MD

Georg Grubhofer, MD

Michael Havel, MDa

Ernst Wolner, MDa
Objective: Protection of the brain is a primary concern in aortic arch surgery. Retrograde cerebral perfusion is a relatively new technique used for cerebral protection during profound hypothermic circulatory arrest. This study was designed to compare, retrospectively, the outcome of 109 patients undergoing aortic arch operation with and without the use of retrograde cerebral perfusion. Methods: Fifty-five patients had profound hypothermic circulatory arrest alone, and 54 patients had supplemental cerebral protection with retrograde cerebral perfusion. Mean age was $61 \pm 13$ years and $58 \pm 14$ years, respectively (mean \pm standard deviation). Twenty-two preoperative and intraoperative characteristics, including age, sex, acuity, presence of aortic dissection, and aneurysm rupture, were similar in the 2 groups $(P>.05)$. Results: Mean circulatory arrest times (in minutes) were $30 \pm 19$ in the group without retrograde cerebral perfusion and $33 \pm 19$ in the group with retrograde cerebral perfusion, respectively. $\chi^{2}$ Analysis revealed that patients operated on with the use of retrograde cerebral perfusion had significantly lower hospital mortality $(15 \%$ vs $31 \% ; P=.04)$ and in-hospital permanent neurologic complications $(9 \%$ vs $27 \% ; P=.01)$. Retrograde cerebral perfusion failed to reduce the prevalence of temporary neurologic dysfunction $(17 \%$ vs $18 \% ; P=.9)$. Stepwise multiple logistic regression revealed that extracorporeal circulation time, age, and lack of retrograde cerebral perfusion were statistically significant independent risk factors for hospital mortality. The same analysis revealed that lack of retrograde cerebral perfusion was the only significant independent risk factor for permanent neurologic dysfunction. Conclusion: Retrograde cerebral perfusion decreased the prevalence of permanent neurologic complications and the hospital mortality in patients undergoing aortic arch operations. (J Thorac Cardiovasc Surg 1999;118:1026-32)
0 perations on the aortic arch still remain a great challenge for cardiac surgeons and necessitate a period of cerebral blood flow interruption. Therefore, it is imperative to protect the brain during this very sensitive time. Profound hypothermic circulatory arrest (PHCA) is now the most commonly used technique for achieving operative exposure and simultaneously protecting

From the Department of Cardiothoracic Surgery, University of Vienna, Austria, ${ }^{a}$ and the Department of Surgery, University of Massachusetts Medical Center, Boston, Mass. ${ }^{\mathrm{b}}$

Received for publication Jan 13, 1999; revisions requested Mar 30, 1999; revisions received Aug 19, 1999; accepted for publication Sept 3, 1999.

Address for reprints: Marek P. Ehrlich, MD, Department of CardioThoracic Surgery, University of Vienna, Währinger Gürtel 18-20, A-1090 Vienna, Austria (E-mail: MEhr198000@aol.com).

Copyright (C) 1999 by Mosby, Inc.

$0022-5223 / 99 \$ 8.00+0 \quad \mathbf{1 2 / 1 / 1 0 2 8 2 2}$ the brain. ${ }^{1,2}$ This surgical method affords adequate time to replace the pathologically altered aorta in a dry and motionless field.

Time limitation is the major drawback of PHCA. It has been clearly shown that the risk of cerebrovascular accidents increases dramatically when circulatory arrest times exceed 45 minutes..$^{3,4}$ Therefore, adjunct methods have been used to extend the "safety-period" of circulatory arrest. These included cerebroplegia ${ }^{5}$ and antegrade perfusion of the cerebral circulation via the innominate arteries. ${ }^{6}$ Retrograde cerebral perfusion (RCP), through a superior vena cava cannula, is a wellestablished, and now commonly used, method for protecting the brain during an aortic arch operation. This new method, originally described for the management of inadvertent air embolism during bypass surgery, ${ }^{7}$ is gaining more acceptance in aneurysm surgery. In 1982, Lemole and associates ${ }^{8}$ described the use of RCP in an 


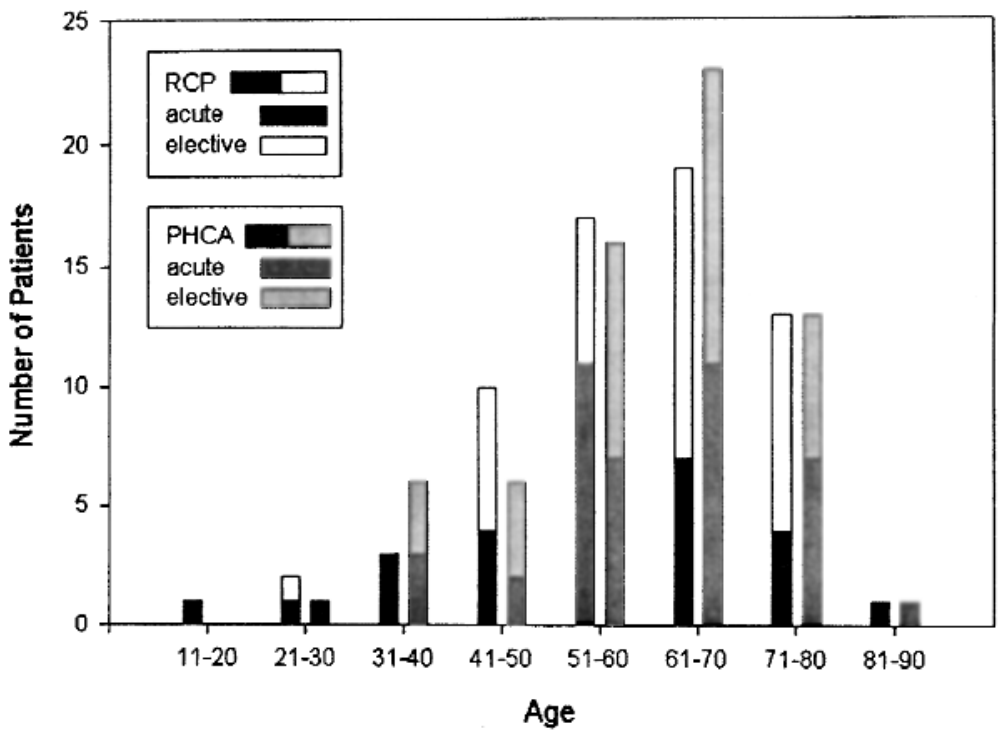

Fig 1. Age distribution and preoperative clinical status (elective, acute) at time of operation.

intermittent fashion, employing this technique for 2 of every 10 minutes of circulatory arrest. The use of RCP in a continuous manner during aortic arch repair, first described by Ueada and colleagues, ${ }^{9}$ is now frequently used for cerebral protection.

The present study was undertaken to compare, retrospectively, our experiences and results in 132 patients undergoing aortic arch operation with and without the use of RCP. Particular emphasis was directed toward mortality and neurologic outcome.

\section{Patients and methods}

Patients. A total of 109 patients underwent surgical repair of the ascending aorta, the aortic arch, or both, at the University of Vienna Medical Center.

The PHCA group, operated on from November 1986 to April 1993, consisted of 39 men and 16 women with ages ranging from 31 to 81 years. The RCP group, in which in addition to PHCA, RCP was implemented, were operated on from May 1993 to December 1998 and comprised 34 men and 20 women with ages ranging from 18 to 81 years. Age distribution showed a predominance in both groups in the sixth decade (Fig 1). For the 5 patients ( 3 in the PHCA, 2 in the RCP group) with Marfan syndrome, the average age was 43 and 33 years, respectively. The groups were not significantly different with respect to a number of preoperative as well as intraoperative variables previously shown to have an impact on outcome in patients with this aneurysmal disease as shown in Table I. Specifically, both groups did not differ significantly with respect to age, sex, dissection, ruptures or hemodynamic instability.

Hypertension was the most common preoperative medical disorder, with a prevalence of more than $80 \%$ in both groups,
Table I. Selected preoperative clinical characteristics and complications in the PHCA and RCP group

\begin{tabular}{|c|c|c|c|}
\hline Variable & PCHA & $R C P$ & $\mathrm{P}$ value \\
\hline Male & $71 \%(39 / 55)$ & $63 \%(34 / 54)$ & .4 \\
\hline Age & $61 \pm 13$ & $58 \pm 14$ & .3 \\
\hline Marfan syndrome & $5 \%(3 / 55)$ & $4 \%(2 / 54)$ & .4 \\
\hline Hypertension & $80 \%(44 / 55)$ & $91 \%(49 / 54)$ & .11 \\
\hline $\begin{array}{l}\text { Coronary heart disease, } \\
\%\end{array}$ & $34.5 \%(19 / 55)$ & $26 \%(14 / 54)$ & .3 \\
\hline $\begin{array}{l}\text { Previous myocardial } \\
\text { infarction }\end{array}$ & $5 \%(3 / 55)$ & $5.5(3 / 54)$ & .98 \\
\hline $\begin{array}{l}\text { Preoperative neurologic } \\
\text { symptoms }\end{array}$ & $0 \%(0 / 55)$ & $4(2 / 54)$ & .14 \\
\hline Pulmonary disease & $2 \%(1 / 55)$ & $7 \%(4 / 54)$ & .16 \\
\hline Renal dysfunction & $2 \%(1 / 55)$ & $5.5 \%(3 / 54)$ & .3 \\
\hline Previous cardiac surgery & $29 \%(16 / 55)$ & $20 \%(11 / 54)$ & .3 \\
\hline Acute & $53 \%(29 / 55)$ & $52 \%(28 / 54)$ & .9 \\
\hline Rupture & $18 \%(10 / 55)$ & $15 \%(8 / 54)$ & .6 \\
\hline Dissection & $64 \%(35 / 55)$ & $70 \%(38 / 54)$ & .4 \\
\hline Hemodynamic instability & $13 \%(7 / 55)$ & $15 \%(8 / 54)$ & .6 \\
\hline \multicolumn{4}{|l|}{ Intraoperative } \\
\hline $\begin{array}{l}\text { Coronary artery } \\
\text { bypass }\end{array}$ & $20 \%(11 / 55)$ & $17 \%(9 / 54)$ & 0.6 \\
\hline $\begin{array}{l}\text { Use of a composite } \\
\text { graft }\end{array}$ & $29 \%(16 / 55)$ & $15 \%(8 / 54)$ & 0.07 \\
\hline
\end{tabular}

followed by presence of a dissection and acuity. Seven patients in the PHCA group and 8 patients in the RCP group were hemodynamically unstable before the onset of cardiopulmonary bypass and cardiac tamponade had already developed. Twenty-seven patients had undergone previous operations on the heart or the thoracic aorta. The cause of aortic disease was dissection type A in 35 patients (26 acute, 


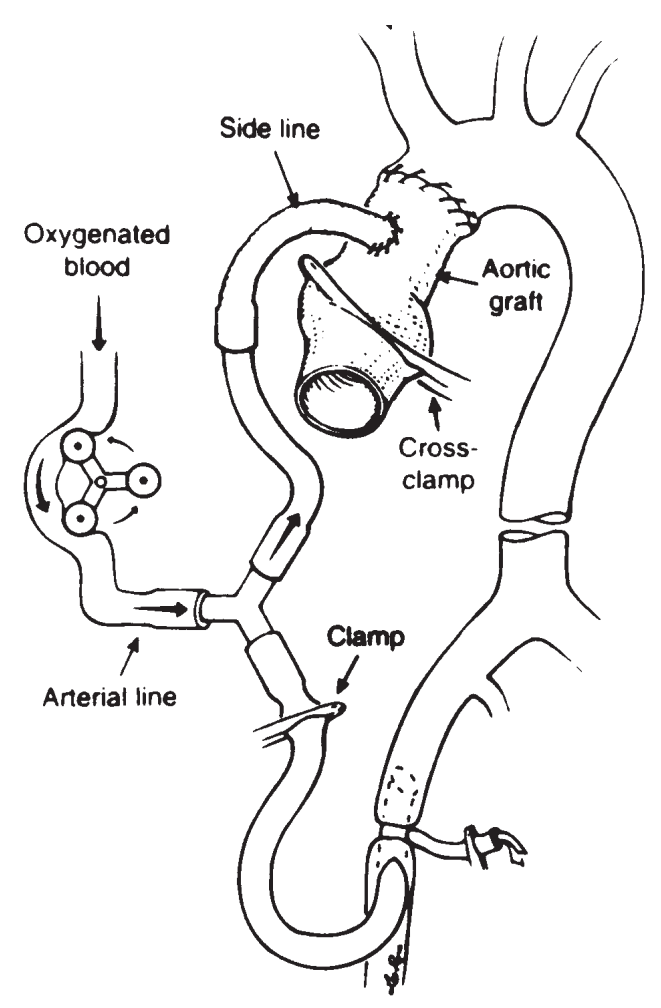

Fig 2. Schematic presentation of method of selective body perfusion through a side-graft in operations performed on ascending aorta and arch.

9 chronic) in the PHCA group and in 38 patients (27 acute, 11 chronic) in the RCP group. Degeneration of the aorta with an increase in the diameter of more than $6 \mathrm{~cm}$ was present in 20 patients in the PHCA group ( 3 acute, 17 chronic) and 16 patients in the RCP group ( 1 acute, 15 chronic).

Attempts were made to repair and resuspend the native aortic valve, whenever possible, except in cases of the Marfan syndrome or severe annuloaortic ectasia. Nevertheless, 32 patients (21 in the PHCA group, 11 in the RCP group) required aortic valve replacement. Composite valve graft replacement with reimplantation of the coronary arteries was performed in 24 patients $(22 \%)$.

The preoperative diagnosis was made by means of either computed tomography (CT), transesophageal echocardiography, or by a combination of both methods.

Definitions of neurologic complications. For the analysis of neurologic outcome, two distinct neurologic end points were defined. First, temporary neurologic dysfunction was defined as the occurrence of postoperative confusion, agitation, or transient delirium. Computed tomographic findings, when obtained for these patients, were usually normal. Second, permanent neurologic deficit was defined as the presence of permanent neurologic dysfunctions that were focal (stroke) or global (coma).

Operative technique. All operations were performed through a median sternotomy. After patients received heparin (300 IU/kg body weight), cardiopulmonary bypass was established through the femoral artery and the right atrium. In patients with cardiac tamponade, the left femoral vein was used for venous access and the patient was first cooled down and the circulation was interrupted before sternotomy.

Once cardiopulmonary bypass was established, systemic cooling was immediately initiated. After onset of ventricular fibrillation, the aorta was clamped and cold blood cardioplegia was administered antegrade or retrograde continuously for myocardial protection. To increase the tolerance of neurologic tissue for ischemia, the patients' heads were packed in ice bags, and $1000 \mathrm{mg}$ of methylprednisolone were given before the onset of HCA. A rectal temperature of $18^{\circ} \mathrm{C}$ and a nasopharyngeal temperature of $11^{\circ} \mathrm{C}$ was considered adequate to start hypothermic circulatory arrest. Blood, 1000 to $1500 \mathrm{~mL}$, was drained into the reservoir of the pump oxygenator system. In patients where RCP was implemented during the period of PHCA, a bypass bridge connecting the arterial and venous lines of the extracorporeal circuit was used to reverse the flow into the superior vena cava cannula. RCP flow rates were adjusted to maintain a mean central venous pressure of $20 \mathrm{~mm} \mathrm{Hg}$. This resulted in a median flow rate of $280 \mathrm{~mL} / \mathrm{min}$ (range, 50-650 $\mathrm{mL} / \mathrm{min}$ ).

Albumin-precoated polyethylene terephtalate (Dacron) grafts (Vascutek; Sulzer Inc, Renfrewshire, Scotland), which had a pre-manufactured 8-mm Dacron side-graft sutured endto-side into the prosthesis, were used in most of the patients. The anastomosis were performed with continuous 4-0 Prolene (Ethicon, Sommerville, NJ) sutures and reinforced with a 3-mm-wide polytetrafluoroethylene felt. After the distal anastomosis was finished, the arterial side graft of the extracorporeal circuit was connected to the 8-mm Dacron side graft of the prosthesis and selective perfusion was installed (Fig 2). This gave us the possibility to begin with the extracorporeal circulation and rewarming of the patient. Meanwhile, the proximal aortic anastomosis was also reinforced with Teflon strips above the level of the coronary ostia and sutured with 4-0 Prolene, resulting in a resuspension of the native aortic valve.

After rewarming was finished, cardiopulmonary bypass was discontinued and the cannulas were removed.

Statistical analysis. All continuous data are expressed as mean \pm SD. Mortality was defined as death that occurred in the hospital. This serves as our primary end point for the study. Statistical comparison between survivors and nonsurvivors was performed by using $\chi^{2}$ analysis and unpaired $t$ test. Fifteen preoperative (operation date, gender, age, Marfan syndrome, hypertension, coronary artery disease, previous myocardial infarction, preoperative neurologic symptoms, pulmonary disease, preoperative renal dysfunction, previous cardiac surgery, acuity, rupture, dissection, and hemodynamic compromise) as well as 7 intraoperative variables (coronary bypass grafting, use of a composite graft, aortic crossclamp time, circulatory arrest time, use of RCP, and rectal and esophageal temperatures before circulatory arrest) were used for the determination of statistically significant risk fac- 
tors for mortality and neurologic complications. Risk factors that were found to have a $P$ value of less than .25 in the univariate analysis were entered into a stepwise multiple logistic regression for mortality prediction. All statistical analysis was performed on Sigmastat and SPSS computer program (SPSS Inc, Chicago, Ill).

\section{Results}

The overall hospital mortality for all patients was $23 \%(25 / 109)$. Seventeen patients $(31 \%)$ died in the PHCA group compared with 8 patients $(15 \%)$ in the RCP group $(P=.04)$. Intraoperative death occurred only in the case of 1 patient (RCP group). Causes of intraoperative or postoperative death are listed in Table II. Multisystem organ failure and myocardial failure (including low cardiac output) were the most common causes of hospital mortality in both groups. Postoperative neurologic deficits were contributing factors in 3 deaths in the PHCA group. By multiple logistic regression analysis, age and RCP were found to be independent predictors of hospital mortality (Table III).

As depicted in Table IV, no differences were found in esophageal and rectal temperature before the implementation of circulatory arrest, aortic cross-clamp, and circulatory arrest time. The mean duration of the latter was 33 minutes in the RCP group and 30 minutes in the PHCA group. Patients operated on with the use of RCP had somewhat longer extracorporeal circulation times $(P=.06)$.

Twenty patients in the PHCA group and 21 patients in the RCP group exceeded circulatory arrest times of greater than 30 minutes, respectively.

A total of 19 patients underwent ascending aortic replacement, 68 patients had ascending aorta and hemiarch replacement. Total arch replacement was performed in 22 patients. Mortality was higher with more extensive replacement: $36 \%$ in total arch replacement, $22 \%$ in hemiarch replacement, and $10 \%$ in patients for whom only the ascending aorta was replaced. There was no statistically significant difference in hospital mortality between total or hemiarch replacement and ascending aortic repair $(P=.15)$

Postoperative permanent cerebral complications (stroke, global) occurred in 15 patients in the PHCA group and in 5 patients in the RCP group $(P=.01)$. Out of these 20 neurologic deficits, 15 were caused by embolic strokes and were focal. They were verified by means of enhanced CT. In 5 patients, the permanent injury was global and not embolic as could best be determined with cerebral CT scans. Multivariate analysis revealed that lack of RCP was the only independent predictor for permanent neurologic complications (Table III).
Table II. Causes of intraoperative and postoperative mortality

\begin{tabular}{lcc}
\hline Causes & $P H C A$ & $R C P$ \\
\hline Intraoperative & & \\
$\quad$ Heart failure & 0 & 1 \\
Postoperative (in-hospital) & & 2 \\
Heart failure & 6 & 3 \\
Multisystem organ failure & 6 & 0 \\
Sepsis & 1 & 0 \\
Stroke & 3 & 1 \\
Myocardial infarction & 1 & 1 \\
Bleeding & 0 & 8 \\
Total & 17 & \\
\hline
\end{tabular}

Temporary neurologic dysfunction occurred in $17.5 \%(19 / 108)$ of patients who survived the initial postoperative period. RCP failed to reduce the prevalence of temporary neurologic dysfunction (17\% vs $18 \% ; P=.9$ ) (Table V). Univariate analysis revealed that acuity and rupture were risk factors for temporary neurologic complications.

\section{Discussion}

Operations on the aortic arch remain a formidable undertaking for cardiac surgeons. Cardiopulmonary bypass and profound hypothermia and circulatory arrest $\mathrm{t}^{2}$ have been major contributors to the surgical treatment of thoracic aortic diseases. Since then, deep hypothermia and circulatory arrest have been a valuable adjunct in aortic surgery, responsible for markedly decreased mortality and morbidity rates in these procedures. ${ }^{12}$

Deep hypothermia provides ample protection of the brain and other important organs, such as the kidneys. Circulatory arrest provides the possibility to perform operations on the aortic arch without placing a clamp on the aortic wall, thereby avoiding clamp injury on fragile dissected aortic tissue. Additionally, this technique represents a way to accomplish the necessary repair in a dry and motionless field, and it enables meticulous inspection of the aortic arch for further intimal tears in aortic dissections.

Neurologic injury as a result of temporary disconnection of cerebral blood flow during the period of circulatory arrest still remains a dreadful complication in operations performed on the aortic arch. The reported prevalence of cerebral complications varies between $7 \%$ and $35 \% .^{13,14}$

Studies suggest the "safe period" of circulatory arrest at a esophageal temperature of $10^{\circ} \mathrm{C}$ to be 40 minutes. ${ }^{15}$ In their large series of 656 patients, Svennson and associates demonstrated that interruption of cerebral blood 
Table III. Stepwise multiple logistic regression for mortality and permanent neurologic dysfunction in patients who underwent surgery for aortic arch aneurysm

\begin{tabular}{lcccc}
\hline Variables & Coefficient $\pm S E$ & Odds ratio & $95 \%$ CL & P value \\
\hline Hospital death & & & & .03 \\
$\quad$ Retrograde cerebral perfusion & $-1.079 \pm 0.51$ & 0.34 & $0.125-0.922$ & $.001-1.083$ \\
$\quad$ Age & $0.04 \pm 0.02$ & 1.04 & $0.089-0.794$ & .01 \\
Permanent neurologic deficit & $-1.327 \pm 0.559$ & 0.27 & \\
$\quad$ Retrograde cerebral perfusion & & & \\
\hline
\end{tabular}

Table IV. Selected surgical characteristics

\begin{tabular}{|c|c|c|c|}
\hline Variable & PHCA & $R C P$ & $\mathrm{P}$ value \\
\hline $\begin{array}{l}\text { Cardiopulmonary bypass } \\
\text { time }(\mathrm{m})\end{array}$ & $169 \pm 52$ & $186 \pm 67$ & 0.06 \\
\hline $\begin{array}{l}\text { Aortic cross clamp } \\
\text { time }(\mathrm{m})\end{array}$ & $107 \pm 40$ & $111 \pm 51$ & 0.7 \\
\hline Circulatory arrest time (m) & $30 \pm 19$ & $33 \pm 19$ & 0.2 \\
\hline $\begin{array}{l}\text { Rectal temperature before } \\
\text { circulatory arrest }\left({ }^{\circ} \mathrm{C}\right)\end{array}$ & $17.8 \pm 2.3$ & $17.1 \pm 2$ & 0.14 \\
\hline $\begin{array}{l}\text { Esophageal temperature } \\
\text { before circulatory arrest }\end{array}$ & $\begin{array}{l}15.2 \pm 2.5 \\
\text { C) }\end{array}$ & $15.7 \pm 1.7$ & 0.11 \\
\hline
\end{tabular}

Values are mean $\pm \mathrm{SD}$.

flow for longer than 40 minutes was associated with a higher risk of neurologic sequelae and that ischemic times greater than 65 minutes were associated with a higher mortality. ${ }^{3}$

We were unable to find a significant effect on mortality from the length of circulatory arrest time or the time of myocardial ischemia or the level of hypothermia. The observation that circulatory arrest time is not a factor for hospital mortality is consistent with the results obtained by Ergin and coworkers ${ }^{4}$ and with a recent study from our own department. ${ }^{16}$ Extracorporeal circulation time, however, was an independent predictor for hospital mortality.

In regard to the patient's age at time of intervention, a sharp increase in mortality in older patients was observed. Age was also, in multivariate analysis, a statistically significant independent risk factor for mortality. The influence of age was also reported by others as the only constant determinant of mortality. ${ }^{4,16}$

Since the use of these 2 different perfusion techniques correlates with the operation date, it was important to include this as part of the analysis to determine which is the true contributor to improving survival. In our analysis, operation date was not a statistically significant risk factor for mortality, both in univariate analysis and in multiple logistic regression.

As a result of the "safe period" of circulatory arrest being a subject of considerable debate, alternative
Table V. Comparisons of postoperative complications between PHCA and RCP group

\begin{tabular}{lclc}
\hline Complications & PHCA & \multicolumn{1}{c}{$R C P$} & P value \\
\hline Pulmonary dysfunction & $25 \%(14 / 55)$ & $19 \%(10 / 53)$ & .4 \\
Sepsis & $27 \%(15 / 55)$ & $19 \%(10 / 53)$ & .3 \\
Renal failure & $25 \%(14 / 55)$ & $15 \%(8 / 53)$ & .18 \\
Reoperation & $22 \%(12 / 55)$ & $23 \%(12 / 53)$ & .9 \\
Transient neurologic & $18 \%(10 / 55)$ & $17 \%(9 / 53)$ & .9 \\
$\quad$ dysfunction & & & \\
Permanent neurologic & $27 \%(15 / 55)$ & $9 \%(5 / 53)$ & .01 \\
$\quad$ complication & & & \\
\hline
\end{tabular}

methods have been employed in recent years to enhance the safety for this operative procedure.

RCP via a superior vena cava cannula is a relatively new and simple technique that has been shown to improve clinical neurologic outcome in patients undergoing operations on the aortic arch and great vessels.

In this retrospective study comparing the outcome of patients who underwent operations on the aortic arch by the use of hypothermic circulatory arrest or PHCA and RCP, statistical analysis revealed that the hospital mortality rate and permanent neurologic complications could be significantly reduced with the use of RCP. Overall hospital mortality rate for the entire cohort of patients was $23 \%$, which is comparable with other series. ${ }^{4}$ However, a decrease in the mortality rate from $31 \%$ in the PHCA group to $15 \%$ in the RCP group was found when both techniques were analyzed independently. Similarly, a decrease in the prevalence of permanent neurologic dysfunction, from $27 \%$ to $9 \%$, was observed in the respective groups. These findings are similar to a recent retrospective analysis of a large clinical series published by Coselli and associates ${ }^{17}$ where $\mathrm{RCP}$ was found to significantly and favorably influence both in-hospital mortality and the prevalence of permanent stroke.

The extent of the aortic replacement in the present series had no significant influence on operative mortality; however, the highest mortality was seen in patients 
with total arch replacement (36\%). These findings are similar to those of other series. ${ }^{3,4}$

Temporary neurologic complications, which are rarely mentioned by others reporting results on thoracic aortic surgery, occurred in 19\% of our patients. In our study, acuity and rupture were predictive factors for this complication. Our findings are contrary to a study performed by Ergin and colleagues ${ }^{4}$ where advanced age and duration of circulatory arrest time were related to temporary dysfunction.

$\mathrm{RCP}$ failed to reduce the prevalence of temporary neurologic dysfunction in this series. We think this finding is due to the fact that RCP is unable to improve the outcome of the subtle brain injury that occurs as a result of circulatory arrest and is manifested by a transient neurologic deficit.

The major beneficial mechanism of action of RCP is still a matter of intense debate. It is probably multifactorial and includes (1) delivering oxygen to the brain, (2) maintaining metabolic function, (3) keeping the brain cool, and (4) flushing out any atherosclerotic debris. ${ }^{18,19}$

Interpreting our results, where most of the procedures on the aortic arch were performed within the safe limits of circulatory arrest, we strongly think that the apparent superiority of RCP over PHCA in this study can be explained by the sustained intracranial cooling during PHCA that is afforded by RCP and may therefore enhance the topical cooling effect of ice-bags around the head. Furthermore, RCP may be ultimately beneficial for the mitigation of cerebral injury by avoidance of air embolization and flushing out debris from the arterial head vessels. Unfortunately, formal psychometric testing was not evaluated in this series.

In conclusion, this comparable retrospective study showed a beneficial effect of RCP in reducing mortality rate as well as the prevalence of permanent neurologic complications in patients undergoing aortic arch aneurysm repair. This method is not the complete answer to brain protection but may enhance, as an additional technical tool, the safety of hypothermic circulatory arrest. Further experimental and prospective, randomized clinical studies are necessary to determine the benefit of RCP in aortic arch surgery.

The major limitation of the present study was that all data were analyzed retrospectively, a process that mandates caution in the interpretation of results. For example, the 2 groups of patients may have been quite different despite of our efforts to eliminate any potential bias by accounting for possible known confounding factors that may have influenced the clinical outcome. Second, the patients who did not have RCP were in the early period of the study and the use of RCP began as early as 1993. Although the operation date was considered as a variable in the statistical analysis, factors such as a "learning curve" of each surgeon over the study period as well as improvement in intraoperative and postoperative care could not be taken into consideration in a retrospective study. Third, no preoperative psychometric analysis to compare the postoperative cognitive problems of these patients has been addressed because half of them were operated on emergently. We strongly believe that a prospective randomized trial needs to be performed to determine the efficacy of RCP in the treatment of aortic arch aneurysms.

\section{REFERENCES}

1. Borst HG, Schaudig A, Rudolph W. Arteriovenous fistula of the aortic arch: repair during deep hypothermia and circulatory arrest. J Thorac Cardiovasc Surg 1964;48:443-7.

2. Griepp RB, Stinson EB, Hollingsworth JF, Buhler D. Prosthetic replacement of the aortic arch. J Thoracic Cardiovasc Surg 1975; 70:1051-63.

3. Svensson LG, Crawford ES, Hess KR, et al. Deep hypothermia with circulatory arrest: determinants of stroke and early mortality in 656 patients. J Thorac Cardiovasc Surg 1993:106:19-31.

4. Ergin MA, Galla JD, Lansman SL, Quintanac C, Bodian C, Griepp RB. Hypothermic circulatory arrest in operation on the thoracic aorta: determinants of operative mortality and neurologic outcome. J Thorac Cardiovasc Surg 1994;107:788-99.

5. Robbins RC, Balaban RS, Swain JA. Intermittent hypothermic asanguineous cerebral perfusion (cerebroplegia) protects the brain during prolonged circulatory arrest. A phosphorus 31 nuclear magnetic resonance study. J Thorac Cardiovasc Surg 1990;99:878-84.

6. Frist WH, Baldwin JC, Starnes VA, et al. A reconsideration of cerebral perfusion in aortic arch replacement. Ann Thorac Surg 1986;42:273-81.

7. Mills NL, Ochsner JL. Massive air embolism during cardiopulmonary bypass: causes, prevention, and management. J Thoracic Cardiovasc Surg 1980;80:708-17.

8. Lemole GM, Strong MD, Spagna PM, Karmilowicz NP. Improved results for dissecting aneurysms: intraluminal sutureless prosthesis. J Thorac Cardiovasc Surg 1982;83:249-55.

9. Ueda Y, Miki S, Kusuhara K, Okita Y, Tahata T, Yamanaka K. Surgical treatment of aneurysm or dissection involving the ascending aorta and aortic arch, utilizing circulatory arrest and retrograde cerebral perfusion. J Cardiovasc Surg 1990;31: 553-8.

10. David TE, Feindel CM. An aortic valve-sparing operation for patients with aortic incompetence and aneurysm of the ascending aorta. J Thorac Cardiovasc Surg 1992;103:617-22.

11. Takamoto S, Okita Y, Ando M, Moroto T, Handa N, Kawashima Y. Retrograde cerebral perfusion for distal aortic arch surgery through a left thoracotomy. J Card Surg 1994;9:576-83.

12. Ergin MA, O'Connor JV, Guinto R, Griepp RB. Experience with profound hypothermia and circulatory arrest in the treatment of aneurysms of the aortic arch: aortic arch replacement for acute arch dissections. J Thorac Cardiovasc Surg 1982;84: 649-55. 
13. Lansman SL, Raissi S, Ergin MA, Griepp RB. Urgent operation for acute transverse aortic arch dissection. J Thorac Cardiovasc Surg 1989;97:334-41.

14. Livesay JJ, Cooley DA, Duncun JM, Ott DA, Walker WE, Reul GJ. Open distal anastomosis: improved results in the treatment of aneurysms of the aortic arch. Circulation 1982;1982:66(Suppl 1):122-7.

15. Ergin MA, Griepp RB. Progress in treatment in aneurysms of the aortic arch. World J Surg 1980;4:535-9.

16. Grabenwoeger M, Ehrlich M, Cartes-Zumelzu F, Mittlboeck M, Weigel G, Laufer G, et al. Surgical treatment of aortic arch aneurysms in profound hypothermia and circulatory arrest. Ann Thorac Surg 1997;64:1067-71.

17. Coselli J, Safi HJ, Brien HW, Winter JN, Thomas AC, Maulsby $\mathrm{RL}$, et al. Brain protection via cerebral retrograde perfusion during aortic arch aneurysm repair. Ann Thorac Surg 1993;56:270-6.

18. Usui A, Hotta T, Hiroura M. Retrograde cerebral perfusion through a superior vena caval cannula protects the brain. Ann Thorac Surg 1992;53:47-53.

19. Usui A, Hotta T, Hiroura M. Cerebral metabolism and function during normothermic retrograde cerebral perfusion. Cardiovasc Surg 1993;1:107-12.

\section{Targeted}

The Journal of Thoracic and Cardiovascular Surgery gives you two tables of contents.

The condensed table of contents tells you at a glance what topics and authors are presented each month. The expanded table of contents gives you a brief abstract of each article. You select only those articles of most interest to you for further reading. 